\title{
Fractionation and ecotoxicological implication of potentially toxic metals in sediments of three urban rivers and the Lagos Lagoon, Nigeria, West Africa
}

\author{
Aderonke O Oyeyiola ${ }^{\mathrm{a}}$, Christine M Davidson ${ }^{\mathrm{b}}$, Kehinde O Olayinka ${ }^{\mathrm{a}}$, and Babajide I. Alo ${ }^{\mathrm{a}}$ \\ ${ }^{a}$ Department of Chemistry, University of Lagos Akoka- Yaba, Lagos, Nigeria \\ ${ }^{b}$ WestCHEM, Department of Pure and Applied Chemistry, University of Strathclyde, 295 Cathedral \\ Street, Glasgow G1 1XL, UK
}

\begin{abstract}
The potential environmental impact of sediment-bound $\mathrm{Cd}, \mathrm{Cr}, \mathrm{Cu}, \mathrm{Pb}$ and $\mathrm{Zn}$ in three trans-urban rivers in Lagos state and in the Lagos Lagoon, was assessed by use of the modified BCR sequential extraction. The quality of the data was checked using BCR CRM 143R and BCR CRM 701. Good agreement was obtained between found and certified/indicative values. Of the rivers, the OdoIyaalaro, was generally the most contaminated and the Ibeshe the least. Higher concentrations of metals were generally found in the dry season compared to the wet season. Cadmium and Zn were released mostly in the acid exchangeable step of the sequential extraction, indicating that they have the greatest potential mobility and bioavailability of the analytes studied. Chromium and $\mathrm{Cu}$ were associated mainly with the reducible and oxidisable fractions, and $\mathrm{Pb}$ predominantly with the reducible and residual fractions. Sediments with the highest pseudototal analyte concentrations also released higher proportions of analytes earlier in the sequential extraction procedure. The study suggests that, during the dry season, PTM may accumulate in sediments in relatively labile forms that are released and can potentially be transported or bioaccumulate in the rainy season. Application of risk assessment codes and Hankanson potential risk indices indicated that Cd was the element of greatest concern in the Lagos Lagoon system. The study indicated that there is a need to strengthen environmental management and pollution control measures to reduce risk from PTM, but that even relatively simple strategies, such as seasonal restrictions on dredging and fishing, could be beneficial.
\end{abstract}

Keywords: potentially toxic elements, lagoon, sediments, sequential extraction 


\section{Introduction}

Sediments are important carriers for trace metals in the hydrological cycle. They also serve as useful indicators of the quality of aquatic systems. Depending on the environmental conditions, sediments may be either a sink or a source, as trace metals are not fixed permanently, but can be recycled through biological and chemical agents, both within the sedimentary compartment and also back into the water column (Salomons and Forstner 1984).

Increase in industrial and human activities has resulted in an increase in the release of various pollutants, including potentially toxic metals (PTM) (Asthana and Asthana 2003). Effluents from these activities eventually find their way into natural waters and, hence, into sediments. This is of particular concern in developing countries where urbanisation and industrialisation are occurring rapidly and in a relatively unregulated fashion, and adequate environmental protection strategies may not yet be in place (Nriagu 1992). Despite their importance, such systems are still relatively rarely studied, though interest in them is increasing (Huang et al. 2013; Manning 2011; Oketola and Osibanjo 2007; Oyeyiola et al. 2013; Qiao et al. 2013).

The Lagos Lagoon is a shallow, brackish coastal lagoon in the western part of Nigeria, and the largest in the West African coast. Lagos State is the most heavily industrialised in Nigeria reported to be home to between 68 and $80 \%$ of the country's medium and large-scale manufacturing industries (Oketola and Osibanjo 2007) - and the City of Lagos is expanding rapidly with the ambition to become an international hub for trade and industry. Odo-Iyaalaro, Shasha and Ibeshe Rivers are the main trans-urban rivers in the state. They receive domestic and industrial waste from numerous sources, and all finally empty into the Lagos Lagoon. The lagoon is dredged, and the sediment is used for building. Lagoon fish are sold in the open market and consumed, and the water is also used for irrigation and recreation. Exposure routes thus exist that could result in significant impact of PTM in the lagoon on human and environmental health.

Even before the onset of rapid development in the region, Ihenyen (1991) claimed that the discharge of industrial effluents had enhanced levels of $\mathrm{Cr}, \mathrm{Cu}, \mathrm{Pb}$ and $\mathrm{Zn}$ in sediments from Lagos Harbour. More recent studies showed that sediment from the western region of the lagoon - where the major 
urban and industrial areas are located - generally contained higher levels of $\mathrm{Cd}, \mathrm{Cu}, \mathrm{Pb}$ and $\mathrm{Zn}$ than sediments from the eastern part (Otitoloju et al. 2007) and that bioaccumulation into edible shellfish was occurring (Otitoloju and Don-Pedro 2004). A more detailed investigation confirmed that sediment PTM concentrations were indeed generally higher along the western margin of the lagoon, and showed that the Odo-Iyaalaro was the most contaminated, and Ibeshe River the least contaminated, of the trans-urban rivers (Oyeyiola et al. 2013). The same study also noted a possible seasonal effect - sediments collected during the dry season often contained higher concentrations of PTM than those collected from the same locations during the rainy season - and highlighted the need for further investigation of the forms of PTM in the sediment as an aid to risk assessment and environmental management.

The total concentrations of PTM in sediment do not provide information about their potential mobility or bioavailability, but this information can be inferred from speciation analysis. Direct speciation analysis can be performed on environmental samples by means of synchrotron based techniques (Butler et al. 2013) but sensitivity is not always sufficient and the specialist instrumentation required is not widely available, especially in developing countries. Instead, researchers typically use procedures such as sequential chemical extraction to infer information on PTM speciation (Bacon and Davidson 2008). Sequential extraction involves the use of a series of reagents to isolate elements from solid samples. Each extractant used is more aggressive compared to the previous one, and aims to solubilise the metals bound in different, operationally-defined, fractions of the soil or sediment substrate.

A large number of sequential extraction schemes have been proposed (Filgueira et al. 2002; Rao et al. 2008) since the early work of Tessier et al. (1979). However, differences in the numbers of steps and reagents used mean that different results are obtained by different methods. To overcome this problem, a group of experts under the auspices of Community Bureau of Reference (BCR) of the European Commission, developed a simple three-step extraction procedure (Quevauviller et al. 1993). This was later revised to include an additional, residual step (an aqua regia digestion) (Rauret et al. 1999). Reference materials (BCR 601 and BCR 701) certified for metals extractable by the BCR procedure were produced for use in validation of extraction results (Pueyo et al. 2001; Quevauviller et al. 1997). The BCR protocols are now applied widely to investigate the potential 
mobility of trace metals, not only in soils and sediments, but also in matrices such as sewage sludge (Perez-Cid et al. 1996), dust (Tokalioglu et al. 2003) and compost (Greenway and Song 2002).

The aim of this research was to use the revised BCR sequential extraction (Rauret et al. 1999) to fractionate $\mathrm{Cd}, \mathrm{Cr}, \mathrm{Cu}, \mathrm{Pb}$ and $\mathrm{Zn}$ in sediments from three trans-urban tributary rivers and the Lagos Lagoon, and, hence, provide the first assessment of the potential mobility, bioavailability and environmental impact of sediment-bound metals in this important, tropical aquatic system.

\section{Experimental}

Sampling and sampling sites

Twenty six surface sediment samples $(0-5 \mathrm{~cm})$ were collected by means of a stainless steel grab sampler into polyethylene containers for transport to the laboratory. The samples came from fourteen sites: three sites within, or close to the mouth of, each of three major rivers (Odo-Iyaalaro:

sites 3, 5, 6; Shasha River: sites 7, 8, 10; Ibeshe River: sites 14, 16, 17) and five sites (19-23) from within the main part of the Lagos Lagoon (see Figure 1). Two samples per site, obtained at different times of year were extracted, except for sites 22 and 23 where only one sample was obtained.

\section{Sample preparation}

Once in the laboratory, the sediment samples were air dried, homogenized in a mortar, sieved to pass through a $2 \mathrm{~mm}$ stainless steel sieve and stored in polyethylene containers.

\section{Apparatus}

The sequential extraction of the analytes from sediment was carried out in $50 \mathrm{ml}$ centrifuge tubes. An end-over-end mechanical shaker was used to agitate the soil-extractant mixture and a centrifuge in separating the extract from the residue. A water bath was the source of heat in the third step of the sequential extraction, whilst digestion of the sediment residue in step 4 was carried out in a laboratory microwave oven (MDS-2000, CEM, Buckingham, UK). The concentrations of Cd, Cr, $\mathrm{Cu}, \mathrm{Pb}$ and $\mathrm{Zn}$ were determined in sediment extracts and digests by means of a flame atomic absorption spectrometer (AAnalyst 200, Perkin Elmer, Seer Green, UK) using an air-acetylene 
flame and previously optimised conditions. All glassware used were soaked in $5 \% \mathrm{HNO}_{3}$ overnight and rinsed with glass distilled water before use.

\section{Reagents}

Stock standard solutions of $\mathrm{Cd}, \mathrm{Cr}, \mathrm{Cu}, \mathrm{Pb}$ and $\mathrm{Zn}(1000 \mu \mathrm{g} / \mathrm{ml})$ were obtained from VWR International. Working standard solution for the calibration of the spectrometer was prepared daily and were reagent matched to the extractant matrix i.e. acetic acid in step 1 etc. All reagents were of analytical grade or equivalent. Distilled water was used for all dilutions. Extractants were prepared according to the procedure of Rauret et al. (1999).

\section{Procedures}

Pseudototal metal contents were determined by microwave-assisted digestion of $1 \mathrm{~g}$ sediment with $20 \mathrm{ml}$ of aqua regia, a mixture of $\mathrm{HNO}_{3}$ and $\mathrm{HCl}(1: 3)$. The digests were filtered using Fisherbrand QL 100 filter paper $(11 \mathrm{~cm})$ into $100 \mathrm{ml}$ standard flasks, made up to the mark with distilled water and stored in plastic bottles at a temperature of $4{ }^{\circ} \mathrm{C}$ prior to analyses.

Sequential extraction was performed using the revised (four step) BCR protocol (Rauret et al. 1999).

Step 1 (exchangeable and acid soluble fraction): $40 \mathrm{ml}$ of $0.11 \mathrm{~mol}^{-1}$ acetic acid was added to $1 \mathrm{~g}$ of the air-dried sediment sample in a $50 \mathrm{ml}$ polyethylene centrifuge tube. The tube was shaken for $16 \mathrm{~h}$ at room temperature at a speed of $23 \pm 1 \mathrm{rpm}$. The extract was separated from the solid residue by centrifugation (3000 rpm for $20 \mathrm{~min}$ ), decanted into a polyethylene bottle and stored at $4{ }^{\circ} \mathrm{C}$. The residue was washed by shaking with $20 \mathrm{ml}$ of distilled water for $15 \mathrm{~min}$, centrifuging and the supernatant discarded.

Step 2 (reducible fraction): $40 \mathrm{ml}$ of $0.5 \mathrm{~mol}^{-1}$ hydroxylamine hydrochloride (adjusted to $\mathrm{pH} 1.5$ by addition of a fixed amount of $\mathrm{HNO}_{3}$ ) was added to the residue from step 1, and the extraction performed as in step 1 above.

Step 3 (oxidisable fraction): $10 \mathrm{ml}$ of $8.8 \mathrm{~mol} \mathrm{l}^{-1}$ hydrogen peroxide was added in aliquots to the residue from step 2 . The vessel was covered loosely and the contents digested at room temperature 
for $1 \mathrm{~h}$ with occasional agitation. It was then placed in a water bath, the contents digested at $85{ }^{\circ} \mathrm{C}$ and the volume reduced to less than $3 \mathrm{ml}$. Another $10 \mathrm{ml}$ of the hydrogen peroxide was added, and

further heated to near dryness. Thereafter, $50 \mathrm{ml}$ of $1.0 \mathrm{~mol}^{-1}$ ammonium acetate (adjusted to $\mathrm{pH} 2$ with $\mathrm{HNO}_{3}$ ) was added, and the extraction performed as in the previous steps.

Step 4 (residual fraction): The residue from step 3 was transferred into a suitable vessel and the metal content determined by microwave-assisted digestion with aqua regia (as described above for pseudototal metal contents).

\section{Results and Discussion}

\section{Quality control}

Certified reference material BCR CRM 143R was used to assess analytical performance during pseudototal digestion and BCR CRM 701 during sequential extraction. BCR CRM 143R is a sewage-sludge amended soil certified for aqua regia soluble PTM, whilst BCR CRM 701 is a lake sediment certified for trace elements extractable by the revised BCR sequential extraction scheme. Found values (Table 1) were within two standard deviations of the certified values for all elements in the aqua regia digests and for most steps of the sequential extraction, and within three standard deviations in all cases, except for steps where certified values were below limits of detection (LOD) e.g. $\mathrm{Cd}$ in step 4 and $\mathrm{Pb}$ in step 1. The precision of results was $<5 \%(\mathrm{n}=5)$ for pseudototal digestion and $<10 \%$ for the sequential extractions, except for $\mathrm{Cu}, \mathrm{Pb}$ and $\mathrm{Zn}$ in step 4 where the RSD values $(\mathrm{n}=3)$ were 19,15 and $12 \%$, respectively.

\section{Pseudototal metal concentrations}

The pseudototal metal concentrations in the sediment samples are shown in Table 2. As previously reported (Oyeyiola et al. 2013) Odo-Iyaalaro appears to be the most consistently polluted of the three rivers. This is expected since numerous industries are situated around it and discharge their effluents into it. Analyte levels in March, toward the end of the dry season, exceeded those in November, just after the end of the wet season, at all three sampling sites. The highest concentrations of $\mathrm{Cr}, \mathrm{Cu}, \mathrm{Pb}$ and $\mathrm{Zn}$ in the Shasha River were found at site 7, which is close to a 
road bridge with high traffic density. As in Odo-Iyaalaro, the sediments collected around the transition from dry to wet seasons (April/May) contained higher levels of metals than those collected at the transition from wet to dry (October/November). The Ibeshe River was generally the least contaminated of the three, except for site 14 where high levels of $\mathrm{Cu}$ were attributed to the discharge of effluent from textiles manufacture. Concentrations of $\mathrm{Cu}, \mathrm{Pb}$ and $\mathrm{Zn}$ were general lower at sampling sites towards the centre of the lagoon (sites 22 and 23) and higher towards the western margin (sites 19-21) reflecting the greater anthropogenic influence in this area. As previously discussed (Oyeyiola et al. 2013) overall metal concentrations were similar to those reported for other tropical lagoon and estuarine systems affected by anthropogenic inputs as a result of rapid urbanisation.

\section{Sequential extraction}

The average fractionation patterns of the potentially toxic elements in sediments of the three rivers and the Lagos Lagoon, as determined by the revised BCR sequential extraction, are shown in Figures 2 and 3. Where no data is presented for a particular site and analyte, this indicates that concentrations found were $<$ LOD for all steps of the extraction. Where values $>$ LOD were obtained in some steps but $<$ LOD in others, a value of half the LOD in the appropriate reagent was plotted. The mean recoveries obtained using the sequential extraction $(\Sigma($ steps $1-4) /$ pseudototal x 100$)$ were: $118 \pm 10 \%$ for $\mathrm{Cd} ; 104 \pm 6 \%$ for $\mathrm{Cr} ; 102 \pm 9 \%$ for $\mathrm{Cu}$; $130 \pm 9 \%$ for $\mathrm{Pb}$; and $105 \pm 5 \%$ for $\mathrm{Zn}$.

Mean values for $\mathrm{Cd}$ and $\mathrm{Pb}$ are influenced by very high recoveries at a small number of sites with concentrations close to LOD values.

Odo-Iyaalaro was the only river with concentration of $\mathrm{Cd}$ high enough to be quantified reliably in BCR extracts. The analyte was found predominantly associated with the exchangeable phase, but was also present in step 2, the reducible phase (Figure 2). This is of considerable environmental concern. High concentrations of $\mathrm{Cd}$ were present at sites 5 and 6 in March; these sites contained the highest proportions of $\mathrm{Cd}$ in $\mathrm{BCR}$ step 1, and BCR step 1 represents the most labile - hence potentially mobile and bioavailable - PTM reservoir in the sediments.

Chromium could not be detected in sequential extracts of sediment samples with low pseudototal concentrations $\left(<17.5 \mathrm{mg} \mathrm{kg}^{-1}\right.$ see Table 2$)$ and levels in several of the sequential extracts for sites 
with higher pseudototal PTM contents also contained Cr levels too close to LOD for reliable quantification by FAAS. Where higher concentrations of $\mathrm{Cr}$ were present, over half the analyte was associated with the oxidisable phase, nominally organic matter and sulfides (Figure 2). The three samples with the highest $\mathrm{Cr}$ concentrations - those obtained from site 3 on the Odo-Iyaalaro in March, and from sites 7 and 8 on the Shasha River in May - showed a different fractionation pattern: although much of the $\mathrm{Cr}$ present was isolated in BCR step 3, as at other sites, a high proportion was also found in association with the reducible phase. This suggests the presence of an additional $\mathrm{Cr}$ input to these samples, distinct in terms of its (operational) speciation. As observed for $\mathrm{Cd}$, there is a suggestion that both higher overall concentrations, and higher proportions of more labile PTM species, were present towards the end of the dry season, than towards the end of the wet season, in the river sediments.

Copper could be detected in all four BCR extracts at all sites (Figure 3). In general, the oxidisable fraction was dominant, as reported previously for this analyte in numerous studies. This fraction is not considered to be particularly readily mobile. It could in principle be released upon introduction of dissolved oxygen to anoxic sediments, for example through dredging of the waterways, but the samples studied here were oxic. Site 14, in the Ibeshe River, contained the highest $\mathrm{Cu}$ concentration measured in the study area and also the highest proportions of $\mathrm{Cu}$ in BCR steps 1 and 2 ( $\Sigma \mathrm{BCR}$ step $1+$ step $2=62 \%$ of the total extractable content in February and $63 \%$ of the total in December). If the textile industry is indeed the source of this contamination, this suggests that $\mathrm{Cu}$ in the textile effluents is in a relatively labile form, with high potential mobility and bioavailability.

Lead was principally associated with the reducible and residual sediment fractions (Figure 3). As already noted for other analytes, there was a tendency for both higher $\mathrm{Pb}$ concentration, and higher proportions of $\mathrm{Pb}$ in more labile forms (i.e. released earlier in the $\mathrm{BCR}$ procedure) to be found in sediments collected during the dry season (approximately November - April) or shortly thereafter (e.g. site 7 on the Shasha River in May).

Zinc was readily quantifiable by FAAS in all sediment fractions and, like $\mathrm{Cd}$, was found to be strongly associated with the acid exchangeable phase. Sediments contained from 40 to $87 \%$ exchangeable Zn, with the exceptions of samples collected in October from site 7, from site 14 on 
both occasions, and from sites 22 and 23. Pseudototal Zn concentrations at these aforementioned sites were generally rather low $\left(<50 \mathrm{mg} \mathrm{kg}^{-1}\right.$ apart from the sediment from site 14 , collected in February) suggesting that they experience less anthropogenic input than, for example, sediments obtained from sites 5 and 6 in March where concentrations were higher and the exchangeable phase was dominant. The presence of $\mathrm{Zn}$ and $\mathrm{Cd}$ in the step 1 extract is possibly due to co-precipitation with calcium and/or magnesium carbonates. The marked similarity in fractionation patterns between $\mathrm{Cd}$ and $\mathrm{Zn}$ suggests that the source(s) of these PTM may be related.

The application of sequential extraction to provide insight into PTM geochemistry in estuaries, lagoons and rivers affected by rapidly industrialisation/urbanisation in developing countries is increasing, with recent examples from Brazil (Canutu et al. 2013), China (Cai et al. 2011; Chen et al. 2010; Huang et al. 2013; Li et al. 2007; Qiao et al. 2013; Wang et al. 2011; Yan et al. 2010) and India (Asa et al. 2013). Comparison between these studies and the current work is hampered by the use of different extraction procedures by different authors (Bacon and Davidson 2008; Oyeyiola et al. 2011). However, several found a high proportion of $\mathrm{Cd}$ associated with relatively labile sediment fractions, although with total $\mathrm{Cd}$ concentrations considerably lower than those found at OdoIyaalaro sites 5 and 6; $\mathrm{Cr}$ was generally found in relatively immobile forms; whilst $\mathrm{Cu}$ showed variable fractionation, sometimes being found mainly associated with more labile phases (Cai et al. 2011) and sometimes mainly with oxidisable and residual phases (Canuto et al. 2013; Chen et al. 2010; Yan et al. 2010). A predominance of relatively labile $\mathrm{Pb}$ species has been previously reported in the Pearl River (Li et al. 2007; Cai et al. 2011) where it was attributed to current anthropogenic inputs. Similarities were also found between fractionation patterns for $\mathrm{Zn}$ in the current study and in rapidly urbanising areas in China, with $>50 \%$ of the analyte released from most samples in the first two steps of the BCR extraction (Cai et al. 2011; Qiao et al. 2013). In contrast, $\mathrm{Cu}, \mathrm{Cr}, \mathrm{Pb}$ and $\mathrm{Zn}$ in sediments from the largest tropical lagoon in India, Chilka lake (Panda et al. 1995) were dominantly associated with the residual fraction, suggesting that, at least in the mid 1990's when the study was conducted, the system was relatively unaffected by anthropogenic input.

Potential seasonal influence on PTM fractionation in tropical lagoon systems does not appear to have been previously investigated, although Davutluoglu et al. (2010) has reported that BCR fractionation patterns for $\mathrm{Cr}, \mathrm{Cu}, \mathrm{Mn}, \mathrm{Ni}, \mathrm{Pb}$ and $\mathrm{Zn}$ in sediments of a Mediterranean lagoon on the 
south coast of Turkey were similar in wet and dry seasons. In the Lagos sediments, not only were analyte concentrations generally higher in the dry season, but there were also higher proportions of PTM present in more labile forms released earlier in the sequential extraction procedures. Where evidence for a seasonal effect was strongest there was also a change in sediment particle size distribution e.g. at site 3 this was 58\% sand $+13 \%$ silt $+28 \%$ clay in March (dry season), but $80 \%$ sand $+7 \%$ silt $+13 \%$ clay in November (wet season), which can be associated with changing hydrogeological conditions (increased water volume and flow rates during the wet season preferentially remove the finer particles). However, these fine particles appear not only to have higher PTM concentrations than the coarser particle size fraction, as might be expected based on their high surface area, but also to contain PTM is more available forms. Further study of PTM load and chemical/mineralogical composition of suspended particles in the Lagos system at different times of year would therefore be of interest.

\section{Ecotoxicological risk assessment}

To assess the risk associated with the sediment, several methodologies may be used. One is the risk assessment code (RAC), which is based on the fraction of PTM in the acid exchangeable fraction (i.e the most mobile fraction) determined with a sequential extraction procedure (Asa et al. 2013; Davutluoglu et al. 2011; Jain et al. 2007; Perin et al. 1985; Yan et al. 2010). Sites may be classified as: no risk (when $<1 \%$ is present in the acid soluble fraction); low risk (1-10\%); medium risk (11$30 \%$ ); high risk (31-50\%) and very high risk (> $50 \%$ ). Based on the RAC values (Table 3), Cd in Odo-Iyaalaro was found to be mostly associated with the very high risk group, where detectable, while levels in the other water bodies were below the LOD of the analytical method. Chromium, $\mathrm{Cu}$ and $\mathrm{Pb}$ varied from no risk to medium risk, while $\mathrm{Zn}$ varied from high risk to very high risk in most of the sites in all the water bodies.

The RAC approach has a shortcoming in that it evaluates the risk associated with each element based on percentages. If a sample with low pseudototal concentration releases a high proportion of analyte in step 1, then a large percentage value will result, even though the absolute acid exchangeable PTM concentration may be small. It also does not consider the fact that different metals affect aquatic organisms differently e.g. Cd is considerably more toxic than $\mathrm{Zn}$. Therefore, another assessment was made using the Hankanson potential ecological risk index (Cai et al. 2011; 
Chen et al. 2010; Hankanson 1980). According to Hankanson, the ecological risk factor for a given substance $\left(E_{r}^{i}\right)$ and the overall risk index $(R I)$ for the water body due to the presence of multiple contaminants in sediment may be estimated from:

$C_{f}^{i}=C_{s}^{i} /_{C_{n}^{i}} \quad E_{r}^{i}=T_{r}^{i} x C_{f}^{i} \quad R I=\sum E_{r}^{i}$

Where $i$ is a specific substance, $C_{f}^{i}$ is the contamination factor, $C_{s}^{i}$ is the measured analyte concentration, $C_{n}^{i}$ is a preindustrial reference level and $T_{r}^{i}$ is a toxic response factor. In the absence of background values for PTM concentrations in sediment in Nigeria, the values presented by the National Oceanic and Atmospheric administration, USA (SQuiRTs 2008) was used, together with the toxic-response factors reported by Cai et al. (2011). These background values are 0.3, 13, 25, 17 and $38 \mathrm{mg} \mathrm{kg}^{-1}$ and the toxic response factors are 30, 2, 5, 5 and 1 for $\mathrm{Cd}, \mathrm{Cr}, \mathrm{Cu}, \mathrm{Pb}$ and $\mathrm{Zn}$, respectively. Table 4 shows how ecological risk factors and risk indices are related to severity of risk (Hankanson 1980), and Table 5 the data for the Lagos sediments.

Table 5 shows that $\mathrm{Cd}$ poses very high ecological risk in Odo-Iyaalaro River, with $E_{r}^{i}$ values up to 3440. Apart from $\mathrm{Pb}$ at site 6 in March (which just exceeds the threshold) and site 7 in May, and $\mathrm{Cu}$ at site 14 in February, all the other metals pose a low potential ecological risk. As noted above, there are specific inputs of $\mathrm{Pb}$ at site 7 due to the proximity of a busy road bridge (Nigeria has not yet banned the use of tetraethyl lead in petrol) and of $\mathrm{Cu}$-rich effluent at site 14 . In terms of overall ecological risk, with the exception of Odo-Iyaalaro, which had high $R I$ values up to 3560 (very high risk) in some locations, the sediments in the Lagos lagoon and tributary rivers do not appear to be of immediate concern in terms of their PTM contents, although continued monitoring is warranted due to the rapidity of development in the region. The $R I$ values were generally higher during the dry season (e.g. March) reflecting the higher concentrations of PTM present.

\section{Conclusion}

The BCR sequential extraction procedure has been used to fractionate PTM in samples from three trans-urban rivers in Lagos state, Nigeria, and in the Lagos Lagoon. Odo-Iyaalaro was the most 
contaminated of the rivers in terms of $\mathrm{Cd}, \mathrm{Pb}$ and $\mathrm{Zn}$. The highest $\mathrm{Cr}$ concentrations were found in the Shasha river, whilst the Ibeshe river, although generally less contaminated than the other tributaries, displayed the highest $\mathrm{Cu}$ concentration at a site strongly affected by effluent from the textiles industry. PTM concentrations in lagoon sediment were generally low at locations towards the centre of the lagoon, but higher along the western margin where the major urban and industrialised areas are located. As reported previously (Oyeyiola et al. 2013) there was a tendency for sediments collected during the dry season to be enriched in PTM relative to those collected during the wet season .

Cadmium (where detectable) and $\mathrm{Zn}$ showed a similarity in their fractionation pattern, with a high proportion found to be associated with the acid exchangeable phase. Chromium and $\mathrm{Cu}$ were mainly associated with the reducible and oxidisable fractions, and $\mathrm{Pb}$ with the reducible and residual fractions. Sediments with higher pseudototal metals contents which, as noted above, were often those sampled during the dry season, generally contained higher proportions of finer particles and of metals in more labile forms (i.e. released earlier in the BCR procedure). This is of environmental concern because it means that, where overall PTM concentrations are highest, the potential for remobilisation and uptake into the food chain is also greatest.

According to both the RAC code and ecological risk coefficient, $\mathrm{Cd}$ poses the highest potential risk to the Lagos lagoon system. Odo-Iyaalaro River can be classified as a river with high to very high ecological risk, while the other 3 water bodies can be classified as low to moderate ecological risk.

Appropriate steps should be taken to limit dredging and use of sediments from the more contaminated areas of the Lagos system, especially during dry periods when higher concentrations of relatively labile metal species appear to accumulate. Measurement of PTM in bottom-dwelling fish, shellfish and crustaceans would be desirable to determine whether bioaccumulation into the food chain is occurring, and to what extent. Additional studies should be carried out to determine whether seasonal trends in PTM concentration and speciation occur in other major tropical lagoon systems that are affected by rapid urban or industrial development and which have pronounced dry and wet seasons, because relatively simple management practices, such as seasonal restrictions on dredging or fishing in specific areas, could reduce the risk to human and environmental health. 


\section{Acknowledgements}

AOO wishes to acknowledge the financial support of the University of Lagos, Nigeria, and the hospitality of the Department of Pure and Applied Chemistry, University of Strathclyde, during a period as a visiting researcher in the UK. 


\section{References}

Asa, S. C., Rath, P., Panda, U. C., Parhi, P. K., \& Bramha C. (2013). Application of sequential leaching, risk indices and multivariate statistics to evaluate heavy metal contamination of estuarine sediments: Dhamara Estuary, East Coast of India. Environmental Monitoring and Assessment, 185, 6719-6737.

Asthana, D. K., \& Asthana, M. (2003). Environment: Problems and Solutions, Chand and Company Ltd. New Delhi

Bacon, J. R., \& Davidson, C. M. (2008). Is there a future for sequential extraction? Analyst, 25, $25-46$.

Bahena-Manjarrez, J. L., Rosales-Hoz, L., \& Carranza-Edwards, A. (2002). Spatial and temporal variation of heavy metals in a tropical estuary. Environmental Geology, 42, 575-582.

Butler, O. T., Cairns, W. R. L., Cook, J. M., \& Davidson, C. M., (2013). Atomic spectrometry update. Environmental analysis. Journal of Analytical Atomic Spectrometry, 28, 177-216.

Cai, J., Cao, Y., Tan, H., Wang, Y., \& Luo, J. (2011). Fractionation and ecological risk of metals in urban river sediments in Zhongshan City, Pearl River Delta. Journal of Environmental Monitoring, 13, 2450-2456.

Canuto, F. A. B., Garcia, C. A. B., Alves, J. P. H., \& Passos, E. A. (2013). Mobility and ecological risk assessment of trace metals in polluted estuarine sediments using a sequential extraction scheme, Environmental Monitoring and Assessment, 185, 6173-6185.

Chen, C., Lu, Y., Hong, J., Ye, M., Wang, Y., \& Lu, H. (2010). Metal and metalloid contaminant availability in Yundang Lagoon sediments, Xiamen Bay, China, after 20 years continusou rehabilitation. Journal of Hazardous Materials, 175, 1048-1055.

Davutluoglu, O. I., Seckin, G., Kalat, D. G., Yilmaz, T., \& Ersu, C. B. (2010). Speciation and implications of heavy metal content in surface sediments of Akyatan Lagoon-Turkey. Desalination, 260, 199-210.

Davutluoglu, O. I., Seckin, G., Ersu, C. B., Yilmaz, T., \& Sari, B. (2011). Metal content and distribution in surface sediments of the Seyan River, Turkey. Journal of Environmental Management, 92, 2250-2259. 
Filgueiras, A.V., Lavilla, I., \& Bendicho, C. (2002). Chemical sequential extraction for metal partitioning in environmental solid samples. Journal of Environmental Monitoring, 4, 823-857.

Greenway, G. M., \& Song, Q. J. (2002). An ultrasound accelerated sequential extraction method and its application for element partitioning studies in compost from mixed waste streams. Journal of Environmental Monitoring, 4, 950-955.

Hankanson, L. (1980). An ecological risk index for aquatic pollution control: A sedimentological approach. Water Research, 14, 975-1001.

Huang, L., Pu, X., Pan, J-F., \& Wang, B. (2013). Heavy metal pollution status in surface sediments of Swan Lake lagoon and Rongcheng Bay in the northern Yellow Sea. Chemosphere, 93, 1957-1964.

Ihenyen, A. E. (1991). Trace metals in the bottom sediments of the harbour of Lagos, Nigeria. Environmental Monitoring and Assessment, 16, 259-264.

Jain, C. K., Malik, D. S., \& Yadav, R. (2007). Metal fractionation study on bed sediments of Lake Nainital, Uttaranchal, India. Environmental Monitoring and Assessment, 130, 129139.

Li, Q., Wu, Z., Chu, B., Zhang, N., Cai, S., \& Fang, J. (2007). Heavy metals in coastal wetland sediments of the Pearl River Estuary, China. Environmental Pollution, 149, 158-164.

Manning, W. J. (2011). Urban environment: Defining its nature and problems and developing strategies to overcome obstacles to sustainability and quality of life. Environmental Pollution, 159, 1963-1964.

Marmolejo-Rodriguez, A. J., Prego, R., Meyer-Willerer, A., Shumilin, E., \& Cobelo-Gracia, A., (2007). Total and labile metals in surface sediments of the tropical river-estuary system of Marabasco (Pacific coast of Mexico): Influence of an iron mine. Marine Pollution Bulletin, 55, 459-468.

Nriagu, J. O. (1992). Toxic metal pollution in Africa. Science of the Total Environment, 121, 1-37.

Oketola, A. A., \& Osibanjo, O. (2007). Estimating sectoral pollution load in Lagos by Industrial Pollution Projection System (IPPS). Science of the Total Environment, 377, 125-141.

Otitoloju, A. A., \& Don-Pedro K. N. (2004). Integrated laboratory and field assessment of PTM accumulation in edible periwinkle Tympanotonus fuscatus var radula (L.) Ecotoxicology and Environmental Safety, 57, 354-362. 
Otitoloju, A. A., Don-Pedro, K. N., \& Oyewo, E. O. (2007). Assessment of potential ecological distruption based on PTM toxicity, accumulation and distribution in media of Lagos Lagoon. African Journal of Ecology, 45, 454-463.

Oyeyiola, A. O., Olayinka, K. O., \& Alo, B. I. (2011). Comparison of three sequential extraction protocols for the fractionation of potentially toxic metals in coastal sediments. Environmental Monitoring and Assessment, 172, 319-327.

Oyeyiola, A. O., Davidson, C. M., Olayinka, K. O., Oluseyi, T. O. \& Alo, B. I. (2013). Multivariate analysis of potentially toxic metals in sediments of a tropical coastal lagoon. Environmental Monitoring and Assessment, 185, 2167-2177.

Panda, D., Subramanian, W., \& Panigrahy, R. C. (1995). Geochemical fractionation of heavy metals in Chilka Lake (east coast of India) - a tropical coastal lagoon Environmental Geology, 26, 199-210.

Perez-Cid, B., Lavilla, I., \& Bendicho, C. (1996). Analytical assessment of two sequential extraction schemes for metal partitioning in sewage sludges. Analyst, 121, 1479-1484.

Perin, G., Craboledda, M., Lucchese, M., Cirillo, R., Dotta, L., Zanette, M. L., \& Orio, A. A. (1985). Metal speciation in sediments of Northern Adriatic Sea-a new approach for environmental toxicity determination. In lekkas, T. D (Ed.), Metal in the Environment, vol. 2, pp. 454-456.

Pueyo, M., Rauret, G., Luck, D., Yli-Halla, M., Muntau, H., Quevauviller, Ph., \& Lopez- Sanchez, J. F. (2001). Certification of extractable contents of $\mathrm{Cd}, \mathrm{Cr}, \mathrm{Cu}, \mathrm{Ni}, \mathrm{Pb}$ and $\mathrm{Zn}$ in a freshwater sediment, following a collaboratively tested and optimised three-step sequential extraction procedure. Journal of Environmental Monitoring, 3, 243-250.

Qiao, Y., Yang, Y., Gu, J., \& Zhao, J. (2013). Distribution and Geochemical speciation of heavy metals in sediments from coastal area suffered rapid urbanisation, a case study of Shantou Bay, China. Marine Pollution Bulletin, 68, 140-146.

Quevauviller, Ph., Rauret, G., Lopez-Sanchez, J. F., Rubio, R., Ure, A., \& Muntau, H. (1997). Certification of trace metal extractable content in a sediment reference material (CRM 601). Science of the Total Environment, 205, 223-234.

Quevauviller, Ph., Ure, A., Muntau, H., \& Griepink, B. (1993). Speciation of heavy metals in soils and sediments. An account of the improvement and harmonization of extraction 
techniques undertaken under the auspices of the BCR of the Commission of the European Communities. International Journal of Environmental Analytical Chemistry, 51, 135-151.

Rao, C. R. M., Sahuquillo, A., \& Lopez-Sanchez, J. F. (2008). A review of the different methods applied in environmental geochemistry for single and sequential extraction of trace elements in soils and related materials. Water, Air and Soil Pollution, 189, 291-333.

Rauret, G., Lopez-Sanchez, J. F., Sahuquillo, A., Rubio, R., Davidson, C., Ure, A., \& Quevauviller, Ph. (1999). Improvement of the BCR three step sequential extraction prior to the certification of new sediment and soil reference materials. Journal of Environmental Monitoring, 1, 57-61.

Salomons, W., \& Forstner, U. (1984). Sediment and transport of metals. Metals in the Hydrocycle, Springer-Verlag, Berlin

SQuiRTs (2008). NOAA Screening Quick Reference Tables, NOAA, available at: http://www.lm.doe.gov/cercla/documents/rockyflats_docs/SW/SW-A-006011.pdf

Tessier, A., Campbell, P. G. C \& Bisson, M. (1979). Sequential extraction procedure for the speciation of particulate trace metals. Analytical Chemistry, 51, 844-851.

Tokalioglu, S., Kartal, S., \& Birol, G. (2003). Comparison of three sequential extraction procedures for partitioning of heavy metals in car park dusts. Journal of Environmental Monitoring, 5, 468-476.

Wang, S., Lin, C., \& Cao, X. (2011). Heavy metals content and distribution in the surface sediments of the Guangzhou section of the Pearl River, Southern China. Environmental Earth Sciences, 64, 1593-1605.

Yan. C., Li, Q., Zhang, X., \& Li, G. (2010). Mobility and ecological risk assessment of heavy metals in surface sediments of Xiamen Bay and its adjacent areas, China. Environmental Earth Sciences, 60, 1469-1479. 
Table 1 Results of analysis of certified reference materials BCR CRM 143R and BCR CRM $701(\mathrm{mg} / \mathrm{kg})$

\begin{tabular}{lllllll}
\hline & & $C d$ & $C r$ & $C u$ & $P b$ & $Z n$ \\
CRM 143R & & & & & & \\
Pseudototal & Certified & $72 \pm 1.8$ & $426 \pm 12$ & $128 \pm 7^{*}$ & $174 \pm 5$ & $1063 \pm 16$ \\
Pseudototal & Found & $72 \pm 4$ & $412 \pm 8$ & $122 \pm 6$ & $172 \pm 8$ & $1070 \pm 10$ \\
& & & & & \\
CRM 701 & & & & & \\
Step 1 & Certified & $7.34 \pm 0.35$ & $2.26 \pm 0.16$ & $49.3 \pm 1.7$ & $3.18 \pm 0.21$ & $205 \pm 6$ \\
& Found & $7.3 \pm 0.5$ & $<2.21$ & $48.2 \pm 2.0$ & $<6.6$ & $215 \pm 15$ \\
Step 2 & Certified & $3.77 \pm 0.28$ & $45.7 \pm 2.0$ & $124 \pm 3$ & $126 \pm 3$ & $114 \pm 5$ \\
& Found & $3.98 \pm 0.2$ & $45.6 \pm 3.5$ & $139 \pm 9$ & $123 \pm 7$ & $122 \pm 7$ \\
Step 3 & Certified & $0.27 \pm 0.06$ & $143 \pm 7$ & $55.2 \pm 4.0$ & $9.3 \pm 2.0$ & $45.7 \pm 4.0$ \\
& Found & $<0.31$ & $146 \pm 2$ & $54.4 \pm 5.3$ & $8.3 \pm 0.7$ & $38.2 \pm 4.0$ \\
Step 4 & Indicative & $0.13 \pm 0.08$ & $62.5 \pm 7.4$ & $38.5 \pm 11.2$ & $11.0 \pm 5.2$ & $95 \pm 13$ \\
& Found & $<0.55$ & $50.0 \pm 1.4$ & $32.4 \pm 6.1$ & $16.2 \pm 2.4$ & $99 \pm 12$ \\
& & & & & &
\end{tabular}

Found results are mean values \pm standard deviation for $n=5$ (pseudototal digestion) and $n=3$ (sequential extraction); $<$ indicates a result below the limit of detection; $*=$ indicative (non-certified) value 
1 Table 2 Pseudototal concentrations of PTM in sediments $\left(\mathrm{mg} \mathrm{kg}^{-1}\right)$

\begin{tabular}{|c|c|c|c|c|c|c|c|}
\hline & Site & & $C d$ & $\mathrm{Cr}$ & $\mathrm{Cu}$ & $P b$ & $Z n$ \\
\hline \multirow[t]{6}{*}{ Odo-Iyaalaro } & \multirow[t]{2}{*}{3} & Mar & $4.8 \pm 0.4$ & $102 \pm 3.3$ & $54.4 \pm 2.3$ & $45.3 \pm 3.7$ & $157 \pm 3$ \\
\hline & & Nov & $<0.9$ & $21.3 \pm 1.2$ & $29.3 \pm 2.2$ & $19.7 \pm 1.2$ & $53.1 \pm 2.7$ \\
\hline & \multirow[t]{2}{*}{5} & Mar & $21.3 \pm 0.6$ & $22.4 \pm 2.1$ & $139 \pm 2$ & $119 \pm 8$ & $777 \pm 16$ \\
\hline & & Nov & $6.9 \pm 0.4$ & $18.2 \pm 1.4$ & $67.4 \pm 3.4$ & $60.6 \pm 3.6$ & $298 \pm 4$ \\
\hline & \multirow[t]{2}{*}{6} & Mar & $34.4 \pm 0.9$ & $30.2 \pm 1.9$ & $185 \pm 2$ & $154 \pm 3$ & $1040 \pm 10$ \\
\hline & & Nov & $2.2 \pm 0.3$ & $19.2 \pm 1.6$ & $48.6 \pm 1.4$ & $43.1 \pm 3.7$ & $165 \pm 3$ \\
\hline \multirow[t]{6}{*}{ Sasha River } & \multirow[t]{2}{*}{7} & May & $<0.9$ & $140 \pm 3$ & $106 \pm 2$ & $202 \pm 5$ & $640 \pm 25$ \\
\hline & & Oct & $<0.9$ & $<17.5$ & $27.9 \pm 1.9$ & $39.5 \pm 1.2$ & $34.6 \pm 3.1$ \\
\hline & \multirow[t]{2}{*}{8} & May & $<0.9$ & $112 \pm 8$ & $33.8 \pm 2.6$ & $44.2 \pm 1.9$ & $112 \pm 12$ \\
\hline & & Oct & $<0.9$ & $40.7 \pm 2.4$ & $<2.1$ & $<15.8$ & $13.0 \pm 1.3$ \\
\hline & \multirow[t]{2}{*}{10} & May & $<0.9$ & $34.2 \pm 1.4$ & $28.0 \pm 0.4$ & $39.2 \pm 1.1$ & $42.1 \pm 1.9$ \\
\hline & & Oct & $1.7 \pm 0.4$ & $35.5 \pm 2.1$ & $64.0 \pm 3.1$ & $104 \pm 7$ & $190 \pm 4$ \\
\hline \multirow{6}{*}{$\begin{array}{l}\text { Ibeshe } \\
\text { River }\end{array}$} & \multirow[t]{2}{*}{14} & Feb & $<0.9$ & $<17.5$ & $332 \pm 11$ & $<15.8$ & $96.9 \pm 8.1$ \\
\hline & & Dec & $<0.9$ & $<17.5$ & $143 \pm 9$ & $26.3 \pm 2.2$ & $43.3 \pm 1.1$ \\
\hline & \multirow[t]{2}{*}{16} & Feb & $<0.9$ & $<17.5$ & $4.2 \pm 0.2$ & $<15.8$ & $4.6 \pm 0.2$ \\
\hline & & Dec & $<0.9$ & $34.4 \pm 1.2$ & $14.2 \pm 0.7$ & $<15.8$ & $13.5 \pm 0.7$ \\
\hline & \multirow[t]{2}{*}{17} & Feb & $<0.9$ & $<17.5$ & $3.4 \pm 0.9$ & $<15.8$ & $6.0 \pm 0.5$ \\
\hline & & Dec & $<0.9$ & $25.7 \pm 1.5$ & $68.2 \pm 2.4$ & $<15.8$ & $27.5 \pm 1.5$ \\
\hline \multirow[t]{8}{*}{ Lagos Lagoon } & \multirow[t]{2}{*}{19} & Sep & $<0.9$ & $34.4 \pm 1.8$ & $35.2 \pm 2.8$ & $33.2 \pm 1.8$ & $237 \pm 14$ \\
\hline & & Dec & $<0.9$ & $34.4 \pm 2.1$ & $33.7 \pm 2.1$ & $33.2 \pm 0.7$ & $164 \pm 8$ \\
\hline & \multirow[t]{2}{*}{20} & Sep & $<0.9$ & $34.4 \pm 1.4$ & $19.5 \pm 1.6$ & 18.2 & $142 \pm 11$ \\
\hline & & Dec & $1.3 \pm 0.2$ & $51.7 \pm 3.2$ & $30.0 \pm 0.8$ & $39.0 \pm 2.3$ & $146 \pm 5$ \\
\hline & \multirow[t]{2}{*}{21} & Sep & $<0.9$ & $25.7 \pm 0.9$ & $43.0 \pm 3.4$ & $39.0 \pm 3.1$ & $246 \pm 11$ \\
\hline & & Dec & $2.1 \pm 0.2$ & $51.7 \pm 4.8$ & $33.7 \pm 1.5$ & $39.0 \pm 3.4$ & $190 \pm 4$ \\
\hline & 22 & Dec & $<0.9$ & $43.0 \pm 3.2$ & $<2.1$ & $<15.8$ & $14.8 \pm 1.9$ \\
\hline & 23 & Dec & $<0.9$ & $42.5 \pm 1.3$ & $<2.1$ & $<15.8$ & $1.3 \pm 0.1$ \\
\hline
\end{tabular}

Results are mean values \pm standard deviation for $n=3 ;<$ indicates a value below the limit of detection. 
5 Table 3 Risk assessment code values calculated for the Lagos sediments (\%) $\dagger$

\begin{tabular}{|c|c|c|c|c|c|c|c|}
\hline & Site & & $C d$ & $\mathrm{Cr}$ & $\mathrm{Cu}$ & $\mathrm{Pb}$ & $Z n$ \\
\hline \multirow[t]{6}{*}{ Odo-Iyaalaro } & \multirow[t]{2}{*}{3} & Mar & 63.7 & 2.68 & 8.02 & 12.5 & 55.0 \\
\hline & & Nov & $*$ & 17.3 & 10.3 & 18.9 & 50.6 \\
\hline & \multirow[t]{2}{*}{5} & Mar & 77.2 & 8.11 & 9.87 & 5.56 & 75.1 \\
\hline & & Nov & 40.3 & 10.6 & 6.05 & 10.0 & 5.08 \\
\hline & \multirow[t]{2}{*}{6} & Mar & 67.5 & 6.12 & 7.53 & 5.33 & 69.1 \\
\hline & & Nov & 46.9 & 9.67 & 11.4 & 13.0 & 53.1 \\
\hline \multirow[t]{6}{*}{ Sasha River } & \multirow[t]{2}{*}{7} & May & $*$ & 4.31 & 6.05 & 2.60 & 41.5 \\
\hline & & Oct & $*$ & $*$ & 6.95 & 13.4 & 26.2 \\
\hline & \multirow[t]{2}{*}{8} & May & $*$ & 3.60 & 14.1 & 12.8 & 87.3 \\
\hline & & Oct & $*$ & 6.25 & $*$ & $*$ & 51.2 \\
\hline & \multirow[t]{2}{*}{10} & May & $*$ & 10.6 & 6.37 & 12.9 & 77.0 \\
\hline & & Oct & $*$ & 6.63 & 6.05 & 6.21 & 40.4 \\
\hline \multirow{6}{*}{$\begin{array}{l}\text { Ibeshe } \\
\text { River }\end{array}$} & \multirow[t]{2}{*}{14} & Feb & $*$ & $*$ & 17.8 & $*$ & 17.1 \\
\hline & & Dec & $*$ & $*$ & 12.7 & $*$ & 17.7 \\
\hline & \multirow[t]{2}{*}{16} & Feb & $*$ & $*$ & 20.6 & $*$ & 39.6 \\
\hline & & Dec & $*$ & 5.92 & 32.9 & $*$ & 40.8 \\
\hline & \multirow[t]{2}{*}{17} & Feb & $*$ & $*$ & 26.3 & $*$ & 51.6 \\
\hline & & Dec & $*$ & 7.31 & 23.7 & $*$ & 52.7 \\
\hline \multirow[t]{8}{*}{ Lagos Lagoon } & \multirow[t]{2}{*}{19} & Sep & $*$ & 5.81 & 7.45 & 15.2 & 58.3 \\
\hline & & Dec & $*$ & 7.67 & 15.9 & 11.6 & 67.7 \\
\hline & \multirow[t]{2}{*}{20} & Sep & $*$ & 6.00 & 8.17 & 15.5 & 48.8 \\
\hline & & Dec & $*$ & 4.68 & 3.69 & 10.7 & 43.7 \\
\hline & \multirow[t]{2}{*}{21} & Sep & $*$ & 4.46 & 3.23 & 16.7 & 54.2 \\
\hline & & Dec & $*$ & 4.23 & 4.74 & 13.6 & 56.7 \\
\hline & 22 & Dec & $*$ & 3.27 & $*$ & $*$ & 9.52 \\
\hline & 23 & Dec & $*$ & 3.78 & $*$ & $*$ & $*$ \\
\hline
\end{tabular}


8 Table $4 \quad$ Ecological risk factors, risk indices and severity of risk (Hankanson 1980)

9

\begin{tabular}{lll}
\hline$E_{r}^{i}$ & $R I$ & Potential ecological risk \\
& & \\
$<40$ & $<150$ & Low \\
$40 \leq E_{r}^{i}<80$ & $150 \leq R I<300$ & Moderate \\
$80 \leq E_{r}^{i}<160$ & $300 \leq R I<600$ & Considerable \\
$160 \leq E_{r}^{i}<320$ & - & High \\
$\geq 320$ & $\geq 600$ & Very high \\
\hline
\end{tabular}

10

11 
12 Table 5 Ecological risk factors and risk indices calculated for the Lagos sediments

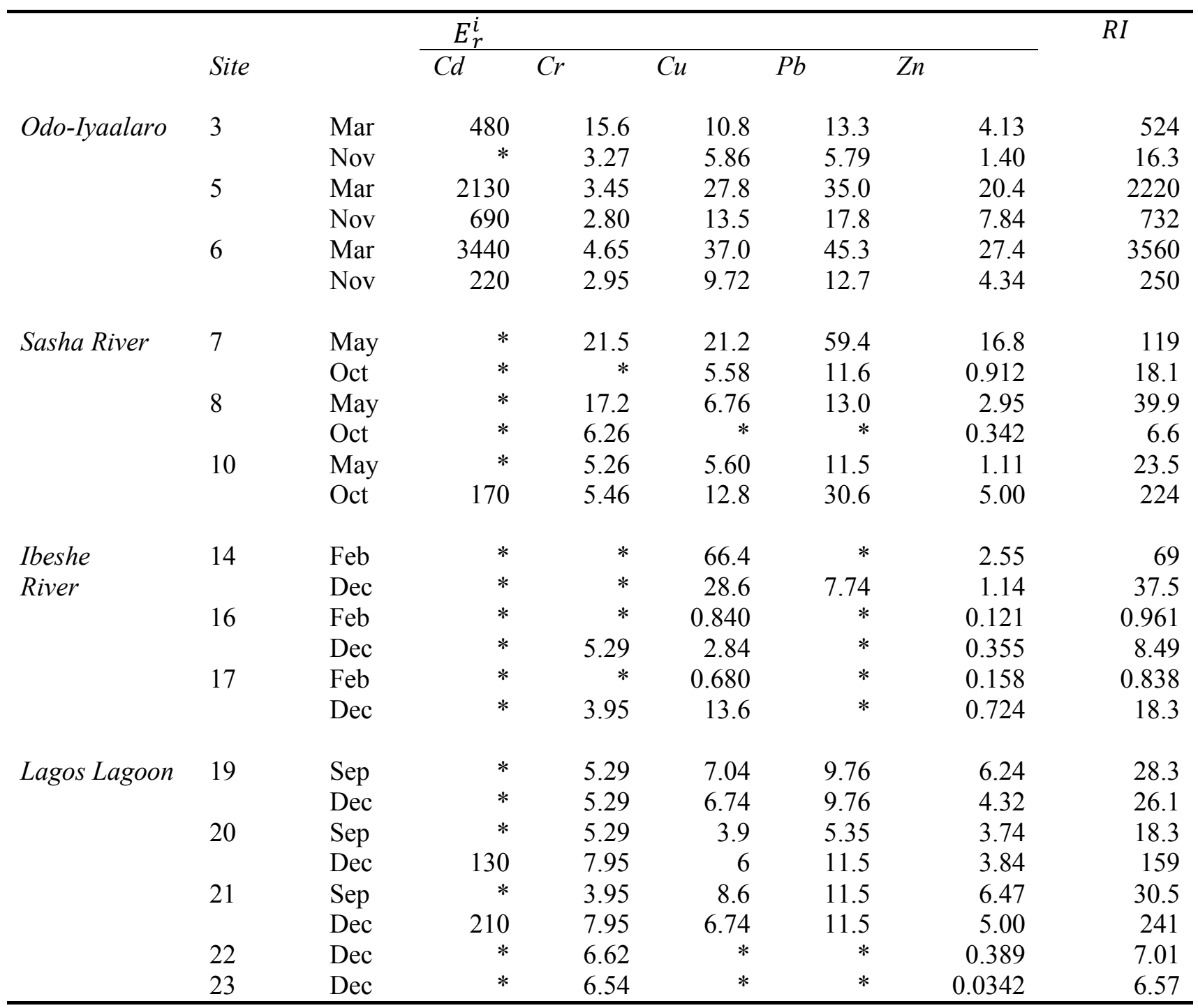


15 List of Figures

16

17 Figure 1

18 Figure 2

19

20 Figure 3

21

22

23
Map of the Lagos Lagoon and tributary rivers

Fractionation of cadmium and chromium in river and lagoon sediments by the BCR sequential extraction procedure.

Fractionation of copper, lead and zinc in river and lagoon sediments by the $\mathrm{BCR}$ sequential extraction procedure 


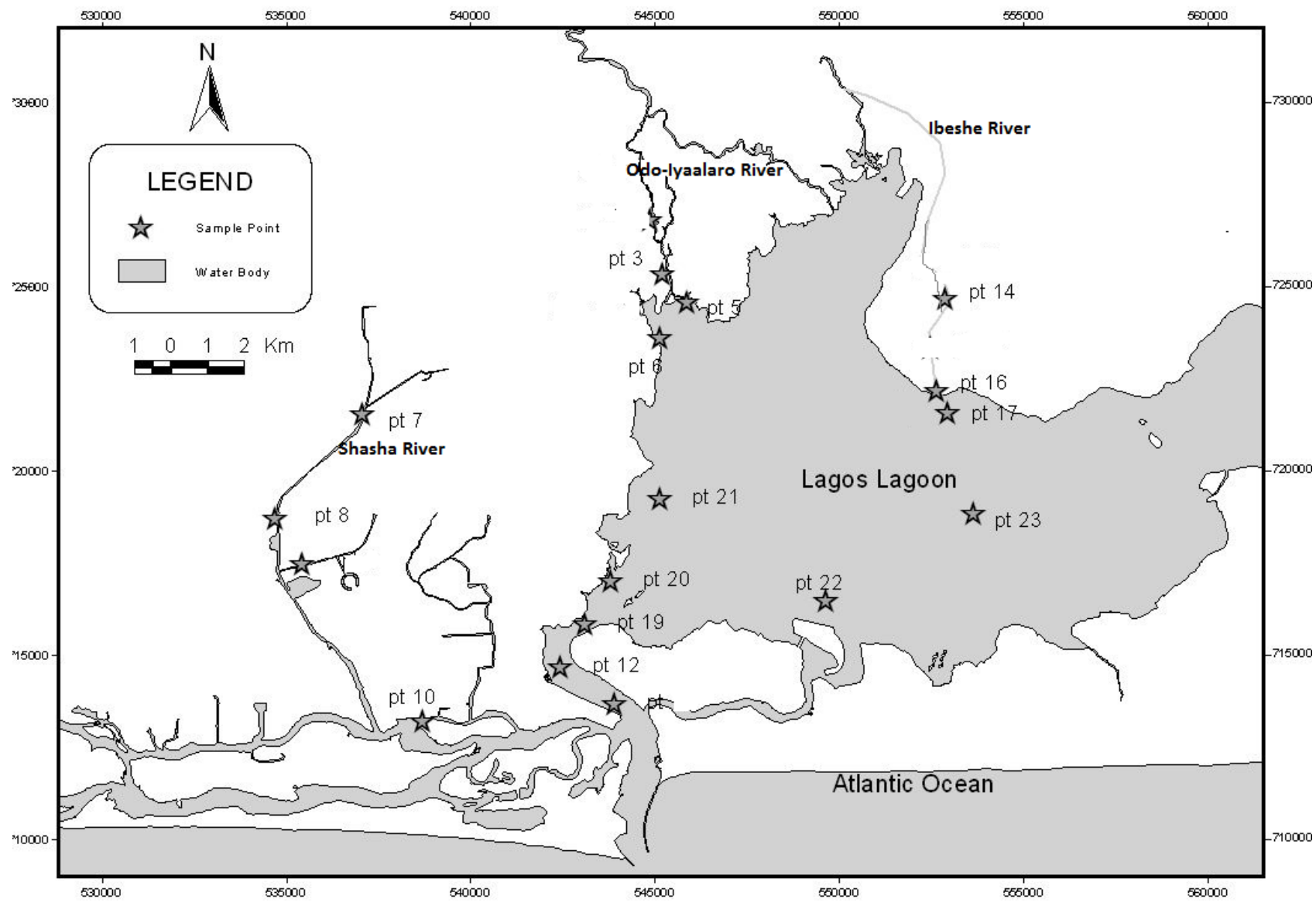




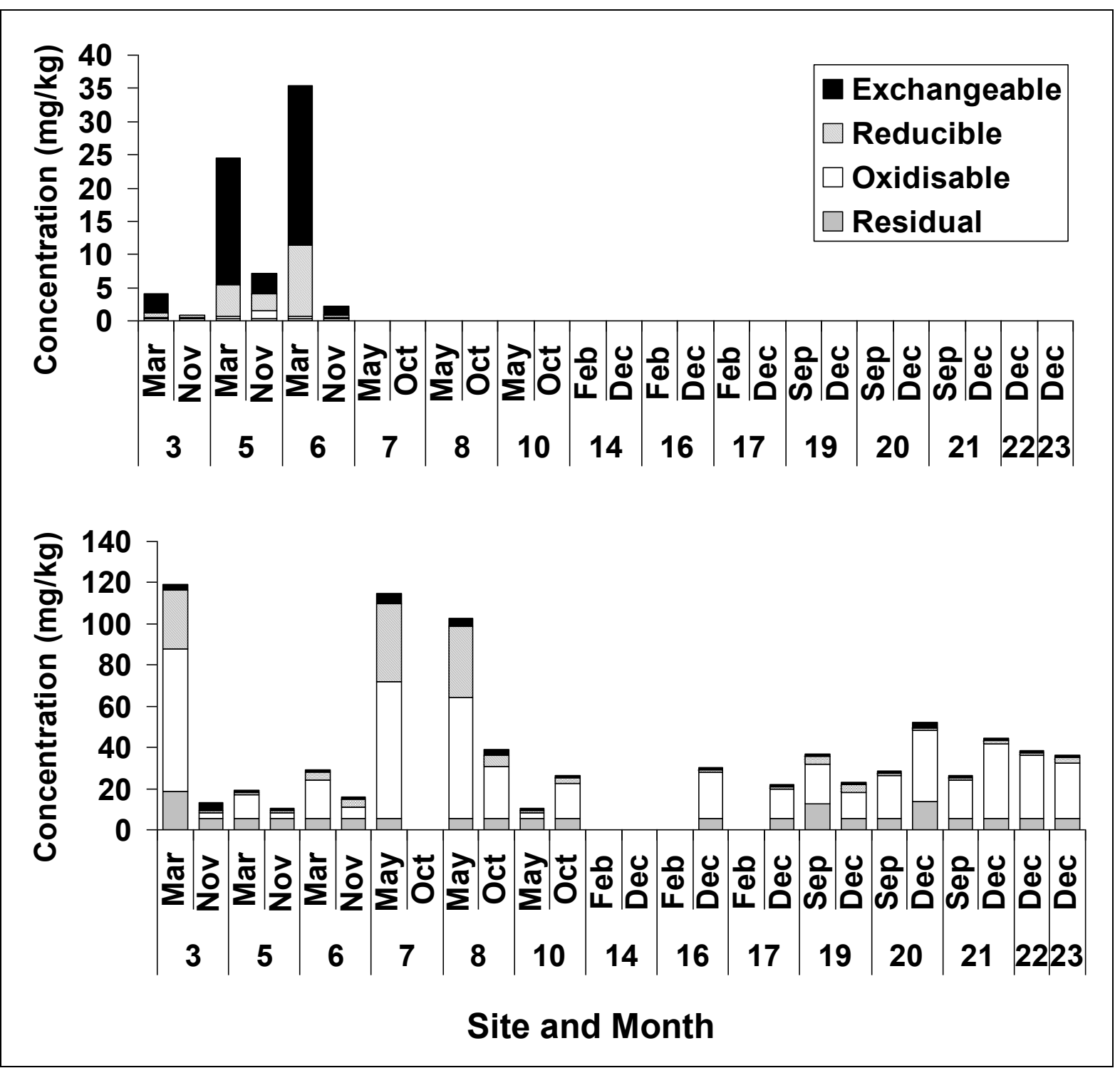



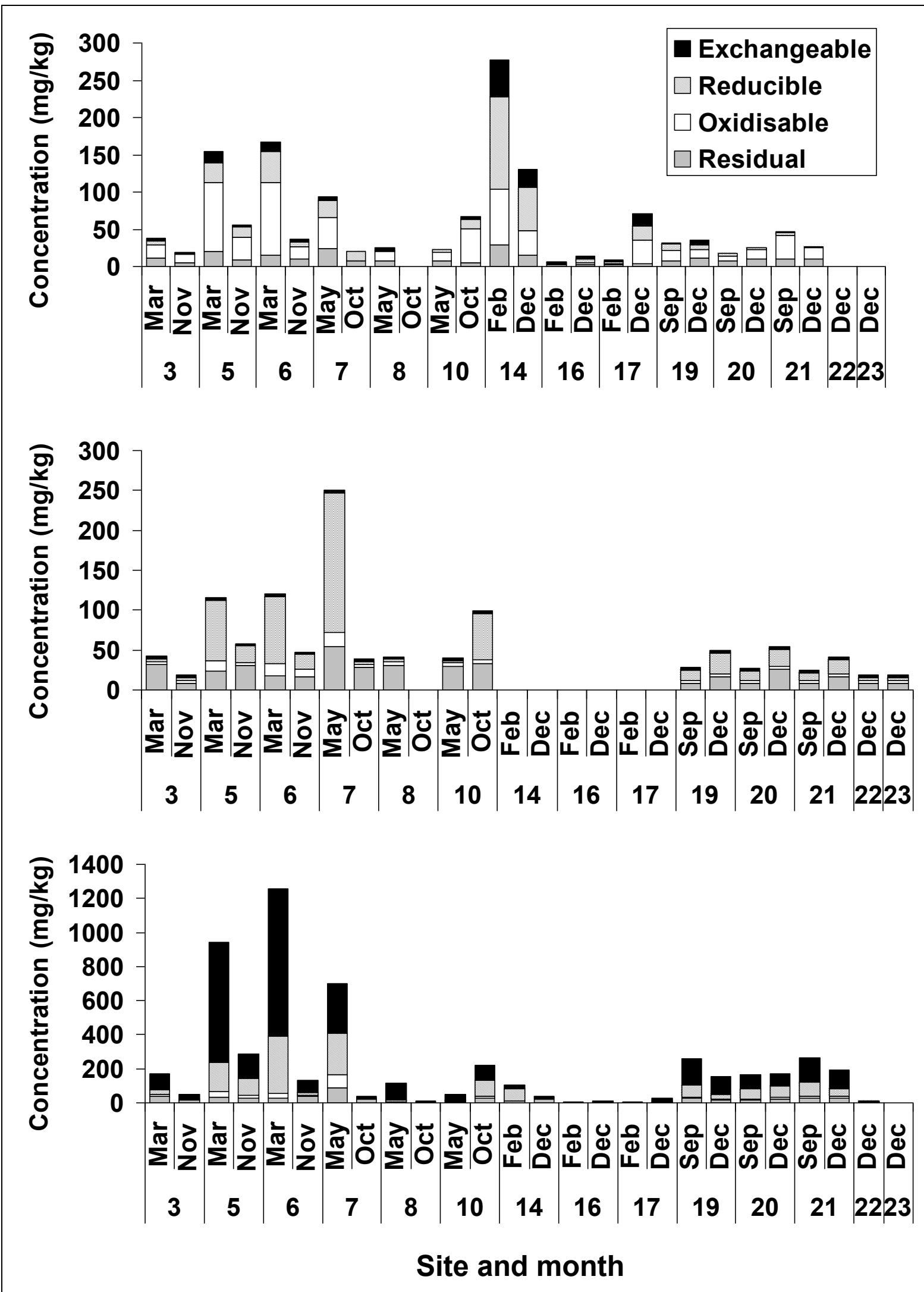
